\title{
Multi-Objective Design Optimisation of Inlet and Combustor for Axisym- metric Scramjets
}

\author{
H. Ogawa ${ }^{1, *}$, R. R. Boyce ${ }^{1}$, A. Isaacs ${ }^{2}$ and T. Ray ${ }^{2}$ \\ ${ }^{1}$ Centre for Hypersonics, School of Mechanical and Mining Engineering, The University of Queensland, St. Lucia, Bris- \\ bane, QLD 4072, Australia \\ ${ }^{2}$ School of Engineering and Information Technology, University of New South Wales, Australian Defence Force Acad- \\ emy, Canberra, ACT 2600, Australia
}

\begin{abstract}
Scramjet airbreathing propulsion is a promising technology for efficient and economical access-to-space. Flow compression in the inlet and fuel combustion in the combustor play a major role in scramjet mechanism, their efficiencies crucially influencing the overall scramjet performance. A double-objective shape optimisation for an axisymmetric inlet and combustor configuration using hydrogen as fuel premixed into air has been performed for minimum total pressure loss and maximum combustion efficiency in the present study. A state-of-the-art MDO (multi-objective design optimisation) capability with surrogate-assisted evolutionary algorithms has been employed, coupled with a CFD solver for inviscid flowfields involving chemical reactions represented by Evans \& Schexnayder's model. The obtained Pareto optimal front suggests the possibility of substantial improvement in efficiency and the counteracting nature of the two objective functions. Geometries with higher combustion efficiency are characterised by a higher compression inlet with larger leading-edge radius and a longer combustor, whereas opposite trends are observed for configurations with smaller total pressure loss.
\end{abstract}

Keywords: Multi-objective design optimisation, axisymmetric scramjet, inlet and combustor.

\section{INTRODUCTION}

Hypersonic air-breathing propulsion offers the potential for reliable and economical systems, providing flexibility for earth-to-space transport as well as atmospheric flight. In particular, scramjet (Supersonic Combustion Ramjet) is a promising technology that can enable efficient and flexible transport systems by removing the need to carry oxidisers and other propulsion limitations of conventional rocket engines.

Supersonic combustion, which plays a key role in the scramjet technology, was first demonstrated in the laboratory in the 1960s [1,2], followed by an extended scramjet research program including airframe integration and combustion testing facility development conducted by NASA Langley Research Center in the 1970s and 1980s [3]. Since then, Australian scramjet research has played a major role and achieved significant milestones in the international effort to develop scramjet technology. Net positive installed thrust for a scramjet vehicle was first demonstrated and measured in the T4 shock tunnel of Centre for Hypersonics of The University of Queensland (UQ) in 1995 [4,5]. In-flight pure supersonic combustion via the use of the scramjet technology was demonstrated at Mach 7.6 for the first time worldwide in UQ's HyShot II program in July 2002 [6,7]. Coming on the heels of these major milestones, the potential of scramjets for propelling high-speed vehicles was demonstrated by NASA's

*Address correspondence to this author at the Centre for Hypersonics, School of Mechanical and Mining Engineering, The University of Queensland, St. Lucia, Brisbane, QLD 4072, Australia; Tel: +61 (0)7 33656073; E-mail: h.ogawa@uq.edu.au
$\mathrm{X}-43$ A scramjet in the Hyper- $\mathrm{X}$ flight program at Mach 6.8 and 9.6 in March and November 2004, respectively [8].

Further breakthroughs have been seen by the first few years of this century in the Australian scramjet research and development. The concept of injecting and mixing in the scramjet inlet rather than the combustion chamber, using localised shock structures in the combustor to achieve ignition even when the mean flow conditions are too mild, was demonstrated successfully in the experiments conducted in the T4 shock tunnel $[9,10]$. It will lead to shorter and lighter scramjets with greater efficiency. An advanced scramjet configuration comprising three-dimensionally curved flowpaths with rectangular-to-elliptical shape transition (REST) has been developed at UQ [11], designed by utilising on the streamline-tracing techniques that have been contrived at NASA Langley Research Center [12]. The REST engines combine ease of vehicle integration with the advantages of elliptical cross-section combustion chambers. Another important concept that has been explored recently is Busemann-type axisymmetric scramjets (Fig. (1)). Combined with the aforementioned "inlet-injection radical farming" concept, this elegantly simple geometry offers numerous advantages in various aspects including aerodynamic and combustion efficiency, thermal and structural management as well as manufacture.

Illustrated in Fig. (2) is a schematic diagram of an axisymmetric scramjet, which consists of an inlet, a combustor and a nozzle, and operates in a sequential process. Hypersonic inflow is compressed to a desired higher pressure (and consequently high temperature) at the exit of the inlet, which induces combustion in the downstream chamber. The reacted 


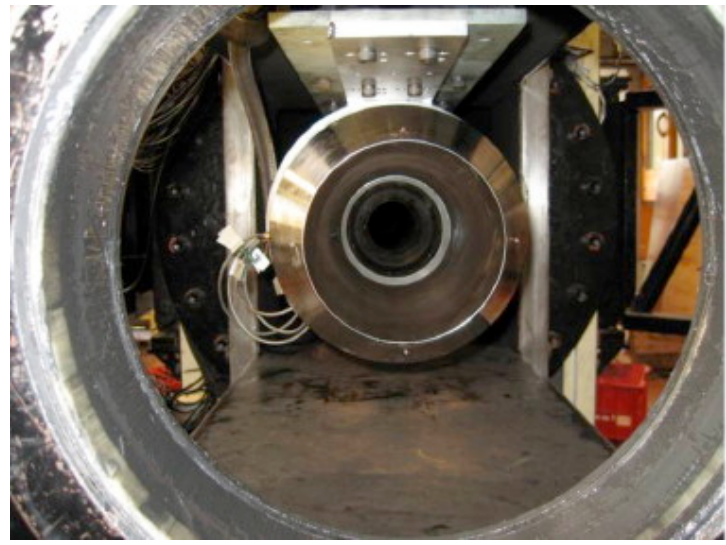

Fig. (1). Axisymmetric scramjet (upstream view).

gas expands in the nozzle to produce thrust. The inlet and combustor, in particular, play a pivotal role in the scramjet mechanism; the combustion critically depends on the temperature of the airflow compressed by the inlet and must take place efficiently within limited time and combustor length, which has a direct impact on the structural weight as well as the overall drag due to immense skin friction on the surface of the combustor.

Scramjet technology has thus advanced to a stage where sophisticated geometries must be explored for increased performance, in particular net positive thrust, which is essential for an access-to-space system. Scramjet engine design, however, represents a formidable challenge to conventional approaches due to the complexity of the associated flowfields involving various aerodynamic and aerothermal phenomena including shock wave / boundary layer interactions, flow separation and chemical reactions. Such a high degree of coupling necessitates the design of the scramjet components in an integrated manner rather than individual. Substantial research efforts have been dedicated to hypersonic design optimisation problems. Early examples include the application of sensitivity-based optimisation algorithms to rather simple configurations such as a scramjet aft body [13] and a two-dimensional scramjet flowpath [14]. An extended design optimisation study has been performed for the engine flowpath of an annular-type scramjet configuration by employing a simplex minimisation algorithm [15].

Recent remarkable advancement of optimisation techniques offers a powerful ability to assist the design process that involves a high degree of complexity. Evolutionary algorithms are particularly attractive for optimisation problems which include complex systems with multiple objectives due to their capability for robust and efficient solution search enabled by population-based probabilistic approaches [16]. A highly advanced MDO capability has been developed at the University of New South Wales campus at the Australian Defence Force Academy (UNSW@ADFA), incorporating these cutting-edge approaches, i.e. evolutionary algorithms assisted by surrogate modelling based on radial basis function networks $[17,18]$. A single-objective design optimisation was preliminarily performed for the nose cone shape of the HyShot fore body as the first example of the application of this surrogate-assisted evolutionary algorithm capability to hypersonic shape optimisation [19]. Other recent examples of surrogate-assisted MDO algorithms for hypersonic applications include the optimisation of fuel injectors for annular scramjet configurations conducted at NASA [20] and AFRL [21] by employing response surface modelling and Kriging surrogates, respectively.

This paper presents the results of a shape optimisation focusing on the inlet and combustor configuration with inviscid assumptions as an intermediate step towards overall vehicle optimisation. A highly sophisticated design methodology coupling the MDO capability and CFD (computational fluid dynamics) has been applied to the shape optimisation of these sections for two primary objectives, i.e. maximum combustion efficiency and minimum total pressure loss, being the first example of the application of the coupled surrogate-assisted MDO / CFD approach to a multi-objective design optimisation problem for the flowpath of a scramjet engine.

\section{APPROACH}

\subsection{Configuration and Conditions}

The schematic diagram of the three-ramp inlet and combustor configuration is shown in Fig. (3), along with the geometry definition by 9 design variables, namely, the ramp lengths $l_{1}, l_{2}, l_{3}$, combustor length $l_{c}$, ramp gradient $\theta_{1}$, ramp gradient increments $\Delta \theta_{2}, \Delta \theta_{3}$, combustor gradient $\theta_{\mathrm{c}}$ and leading-edge nose-tip radius $r_{t}$ (note that the nozzle and external geometries are not considered in this study). The radius of the combustor is fixed at $r_{c}=0.0351 \mathrm{~m}$ at its entrance, based on the specifications of the reference geometry. To avoid the complexity and computational expense of 3D fuel injection flow calculations, premixed fuel and air is assumed for the inflow and inviscid flow fields are assumed in this study in order to focus on the geometric influence on the engine performance, ruling out viscous effects at this stage. The inflow conditions are $M_{\infty}=8.0, p_{\infty}=1197 \mathrm{~Pa}, T_{\infty}=226.5 \mathrm{~K}$ at an operating altitude of $30 \mathrm{~km}$, assuming scramjet operation on a typical trajectory with a constant dynamic pressure of $53.6 \mathrm{kPa}$.

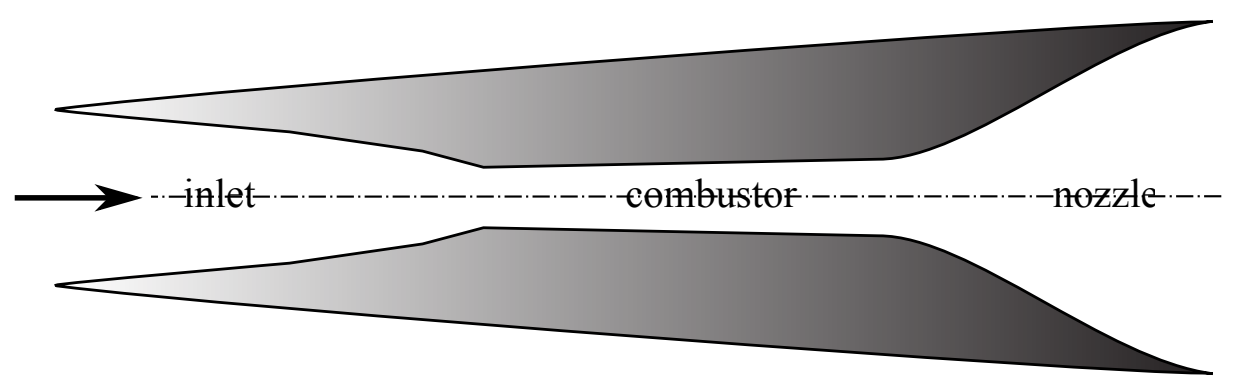

Fig. (2). Schematic diagram of an axisymmetric scramjet. 


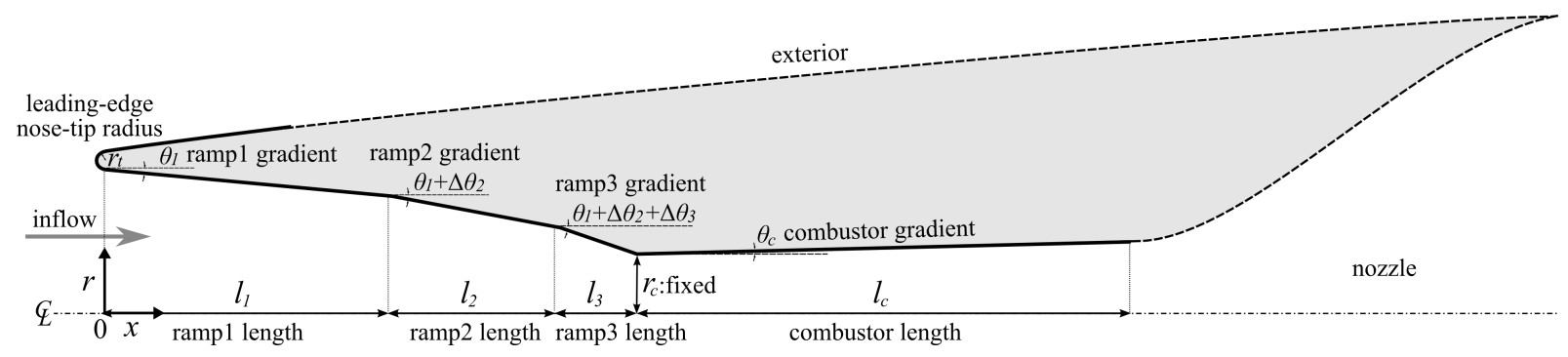

Fig. (3). Schematic diagram of scramjet geometry and parametric representation of inlet \& combustor configuration.

\subsection{Evaluation of Efficiencies}

The performance of this configuration is evaluated by the combustion efficiency and total pressure loss. The combustion efficiency $\eta_{c}$, which is to be maximised, is measured by the consumption of the fuel, for which hydrogen is used in the present study:

$\eta_{c} \equiv 1-\overline{c_{\mathrm{H}_{2} e}} / \overline{c_{\mathrm{H}_{2} i}}$

where the hydrogen mass flux at the station of interest is defined by $\overline{c_{H_{2}}}=\int_{x} c_{H_{2}} \rho u d A$ and the mass fraction of the premixed inflow with an equivalence ratio of 0.8 is $c_{\mathrm{H}_{2} \mathrm{i}}=0.0228$.

The mass-averaged total pressure loss $\Delta p_{0}$, which is to be minimised (and simply referred to as "total pressure loss" from here on), is defined as the decrease in the massaveraged total pressure:

$$
\Delta p_{0} \equiv 1-\overline{p_{0 e}} / \overline{p_{0 i}}
$$

where the mass-averaged total pressure at the station of interest is defined by $\overline{p_{0}}=\int_{x} \rho u p_{0} d A$ and the freestream total pressure is $p_{0 \infty}=1.719 \times 10^{7} \mathrm{~Pa}$.

\subsection{Computational Fluid Dynamics}

A state-of-the-art commercial code CFD++ [22] with highly efficient algorithms is used to solve the compressible Euler equations for steady flow fields involving finite-rate chemical reactions. The gas composition is represented by Evans and Schexnayder's model [23], which consists of 25 elementary reactions among 12 species including hydrogenair combustion as well as nitrogen chemistry. This combustion scheme has been chosen here due to the demonstrated fidelity for scramjet combustion, especially with respect to the prediction of ignition. Structured two-dimensional meshes are generated by Glyph scripting on a commercial grid generator Pointwise [24], based on the geometry representation with the 9 design variables. The mesh comprises 102,286 cells $(515$ nodes in circumferential $\times 200$ nodes in wall-normal direction).

This mesh resolution has been chosen, based on the sensitivity observed in a preliminary mesh dependency study comparing flowfields with a coarse $(515 \times 50$ nodes $)$, medium $(515 \times 100)$, semi-fine X $(1029 \times 100)$, semi-fine Y $(515 \times 200)$, fine $(1029 \times 200)$ and superfine $(2057 \times 400)$ mesh; Fig. (4) compares the profiles of the hydrogen mass fraction $c_{H_{2}}$ at the exit plane of the combustor. A notable difference can be seen near the centreline $(r=0)$, where noticeable combustion occurs only with meshes containing a larger number of cells $(\geq 400)$ in the wall-normal direction. This is found to result from significantly underestimated near-axis temperature with coarse meshes. The semi-fine $\mathrm{Y}$ mesh has been selected for the present study to strike balance between computational cost and fidelity.

\subsection{Optimisation}

An advanced MDO capability developed at University of New South Wales at Australian Defence Force Academy (UNSW@ADFA) [17,18] is utilised to optimise the inlet \& combustor geometry represented by a set of design variables shown in Fig. (3). In particular, use is made of the elitist non-dominated sorting genetic algorithm (NSGA-II) [25] assisted by surrogate modelling. The optimisation chain consists of automatic mesh generation and CFD run followed by evaluation of the solutions. Optimisation occurs over a number of generations with a population of 20 individuals till convergence is reached. The process is assisted by radialbasis-function network surrogate modelling once a sufficient number of solutions have been obtained in the archive by actual CFD evaluations. A simulated binary crossover and polynomial mutation are used as recombination operators with a probability of 1.0 and 0.1 , respectively. The distribution index of the recombination and mutation operators is 10 and 20, respectively. The surrogates are trained by using $90 \%$ of the solutions from the archive, while the remaining $10 \%$ is used for validation. All individuals in the population are evaluated by actual CFD runs every 5 generations. The

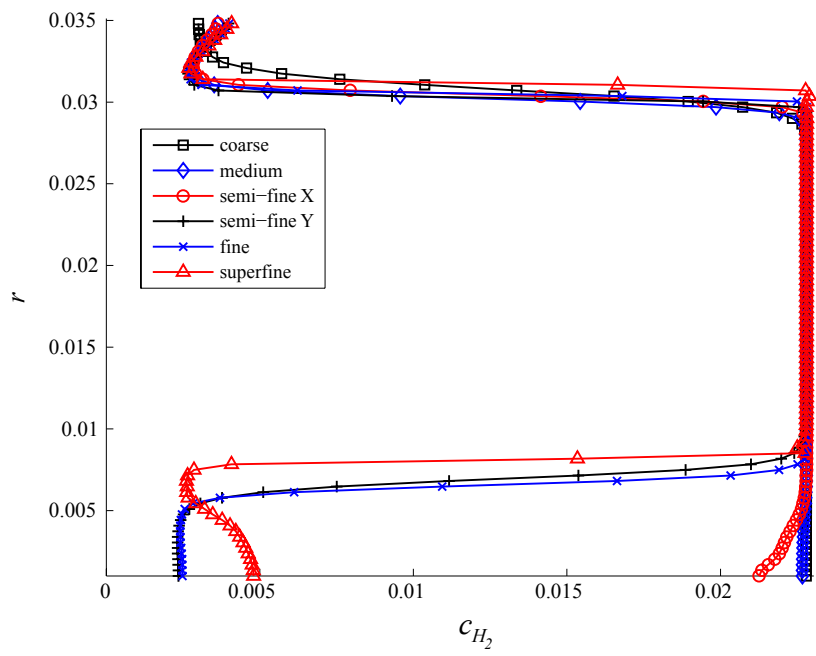

Fig. (4). Hydrogen mass fraction profiles at combustor exit due to various mesh resolutions. 


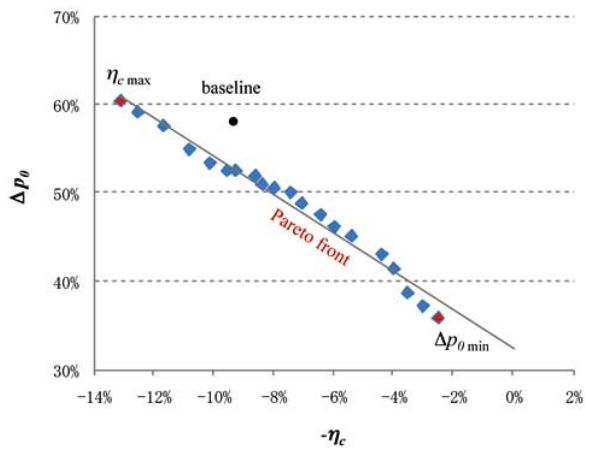

Fig. (5). Pareto front of double-objective optimisation (after 25 generations).

feasibility of solutions is judged by a constraint which assesses the validity of CFD computation based on the residual convergence in order to prevent unconverged hence unphysical solutions with spurious superior objective values from being considered as elitists. The optimisation problem statement of this study is:

maximise: combustion efficiency $\eta_{c}$

minimise: total pressure loss $\Delta p_{0}$

subject to: CFD residual convergence $<10^{-2}$

design variables: $x_{L i} \leq x_{i} \leq x_{U i}(i=1, \ldots, 9)$

where $x_{L i}$ and $x_{U i}$ are the lower and upper bounds of the variables, respectively. These bounds have carefully been chosen in a preliminary study in order to allow reasonable flexibility for the variation of the geometry, while avoiding creation of impractical designs.

\section{RESULTS}

\subsection{Optimisation}

A nearly linear Pareto optimal front has been obtained after 25 generations of optimisation, as shown in Fig. (5) along with a trend line (note that the $x$ axis is $-\eta_{c}$ due to the conversion of combustion efficiency maximisation problem into a minimisation one by multiplying the objective function by 1 , based on the duality principle [26]). The plot clearly shows the counteracting tendency of the two objective functions, namely, $\Delta p_{0}$ and $-\eta_{c}$, in agreement with the observation noted in Reference [27]. The values of the baseline geometry are also plotted in the graph. It indicates the possibility of a reduction of $5.8 \%$ in the total pressure loss $\Delta p_{0}$ and an increase of $2.7 \%$ in the combustion efficiency $\eta_{c}$ when the levels of $\eta_{c}$ and $\Delta p_{0}$ are maintained, respectively.

The values of the objective functions and those of the design variables are compared in Fig. (6) for the two extreme cases of the maximum combustion efficiency $\eta_{c}$ and the minimum total pressure loss $\Delta p_{0}$ (denoted in Fig. 5) as well as the baseline values for reference (note that the values of the design variables are normalised with respect to their range limited by the lower and upper bounds, i.e. $x_{L i}$ and $x_{U i}$, whose values are displayed in the graph). It can be seen that the maximum combustion efficiency of $13 \%^{1}$ (40\% gain

${ }^{1}$ It has later been found in a full flow-path optimisation study [28] that this rather low combustion efficiency can be ascribed to the mild compression due to the fixed combustor radius at the entrance. In spite of this fact, however, this parameter $r_{c}$ is fixed as

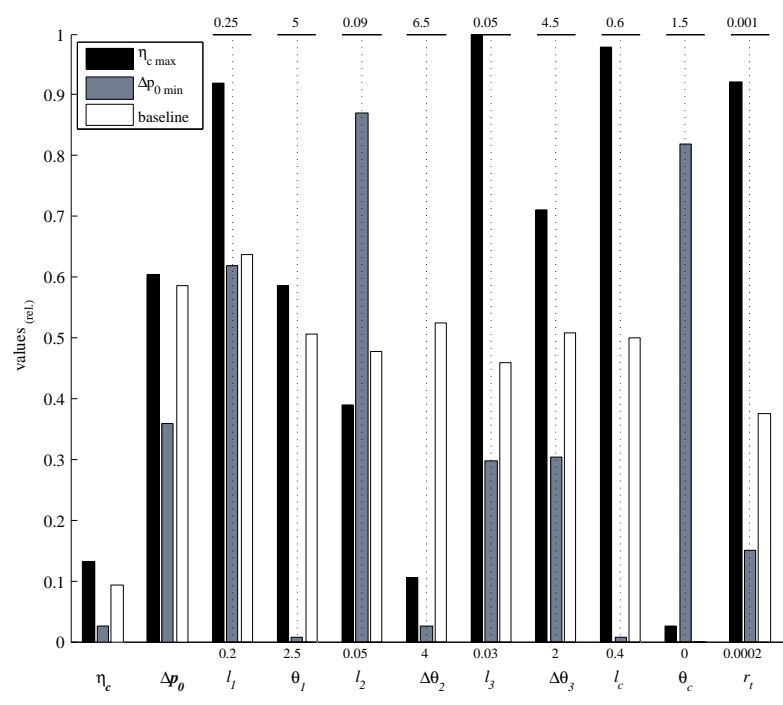

Fig. (6). Objective functions and design variables of optimised and baseline geometries.

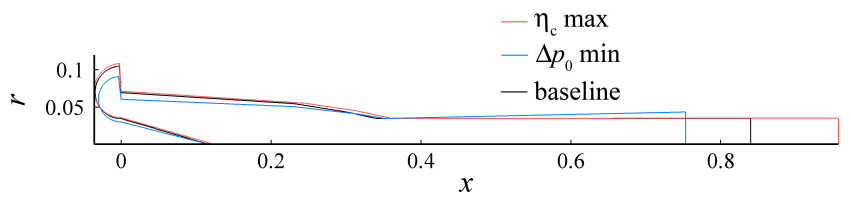

Fig. (7). Bounds of computational domains for optimised and baseline geometries.

from the baseline value) and the minimum total pressure loss of $36 \%$ (39\% saving from the baseline) can be attained in these cases, at the expense of a large total pressure loss and a poor combustion efficiency, respectively.

The optimised shapes are compared with the baseline geometry in Fig. (7), where several distinct features can be found: the maximum combustion efficiency is achieved with a higher contraction hence compression inlet and a longer combustor section, whereas the minimum total pressure loss is achieved with a lower compression inlet and a shorter and diverging combustor. These tendencies can also be seen in the values of the gradient angles $\theta^{\prime}$ s and increments $\Delta \theta^{\prime}$ 's as well as the lengths of the components l's in Fig. (6).

\subsection{Flowfields}

The computed flowfields are compared in Figs. (8 and 9) in terms of the Mach number and temperature distributions, respectively. The maximum $\eta_{c}$ geometry (a) is featured by a near-wall region with high temperature and low Mach number. This results from a comparatively large nose-tip radius $r_{t}$ as seen in Fig. (6) and hence a bow shock at the inlet leading edge, downstream of which high pressure and temperature gas is present and carried all the way to the combustor exit along the wall. The high temperature in the vicinity of the wall leads to a large degree of combustion in this region, as represented by higher mass fraction concentration of $\mathrm{H}_{2} \mathrm{O}$, which is generated as a product of combustion, in Fig. (10). The minimum $\Delta p_{0}$ geometry (b), on the other hand, is characterised by a relatively higher Mach number Fig. (9) inside

a constant in the present study because it would otherwise conceal the effects of the other variables, which are less dominant than that of the combustor radius. 


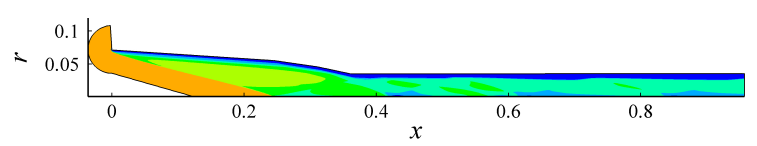

(a) $\eta_{\mathrm{c}} \max$

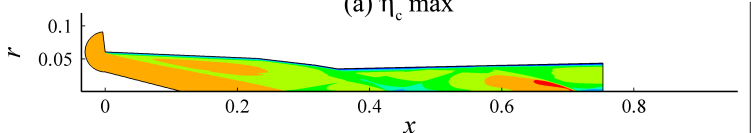

(b) $\Delta p_{0} \min$

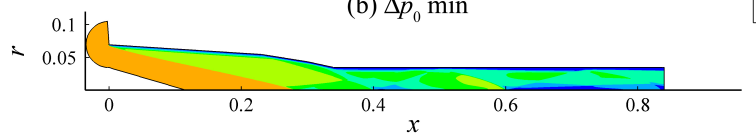

(c) baseline

Fig. (8). Mach number distributions for optimised and baseline geometries.

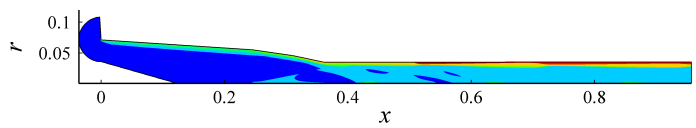

(a) $\eta_{c} \max$

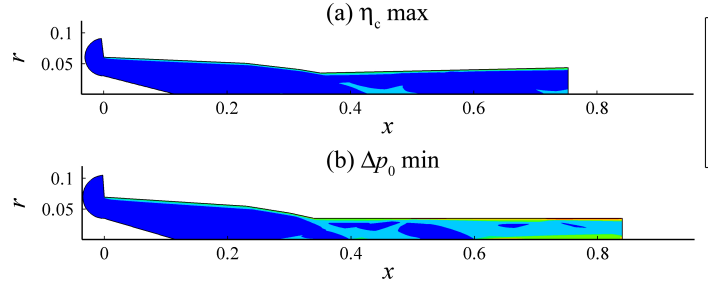

(c) baseline

Fig. (9). Temperature distributions for optimised and baseline geometries.

the combustor due to lower compression in the inlet and by the presence of expansion in the combustor due to the diverging section. This flow expansion results in lower temperature both at the centreline and the wall (Fig. (9)), where combustion is suppressed, effectively saving the total pressure, as observed in Fig. (10). It is noteworthy that for maximum $\eta_{c}$ the optimisation algorithm has chosen to maximise combustion in the near-wall region by increasing the leading-edge nose-tip radius $r_{t}$, disregarding combustion in the centreline region, in contrast with the baseline case. This can be attributed to the mass-weighted definition of $\eta_{c}$ in (1), where the value of $d A$ is greater at off-axis positions due to larger circumferential length, while the mass flow $\rho u$ is comparable to near-axis values even in the near-wall regions in the inviscid flow regime considered in the present study.
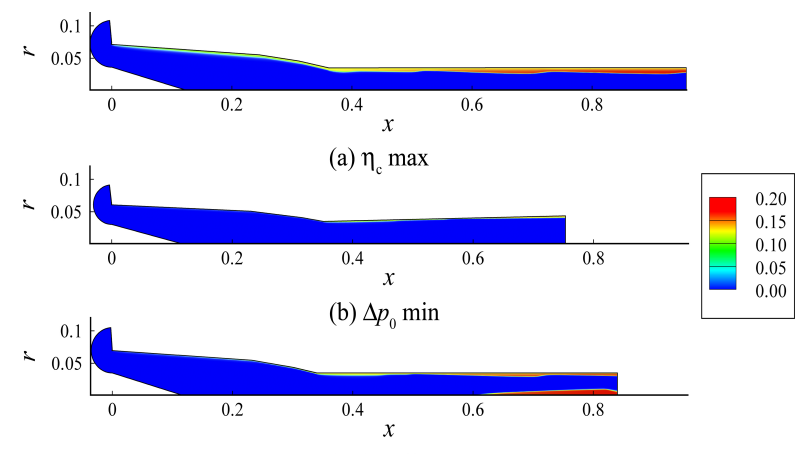

(c) baseline

Fig. (10). $\mathrm{H}_{2} \mathrm{O}$ distributions for optimised and baseline geometries.
The temperature distributions are compared in Figs. (11 and 12) on the wall and at the centreline, respectively. A successive increase of wall temperature is observed in the combustion chamber in the maximum $\eta_{c}$ and baseline case Fig. (11) due to heat release associated with combustion once fuel ignition is initiated by high temperature, whereas too mild compression in the inlet and expansion in the combustor keeps the gas from combustion throughout in the minimum $\Delta p_{0}$ case. The centreline temperature distributions in Fig. (12) show an evident rise due to heat release in the combustor of the baseline configuration, which has been disregarded in the case of the maximum $\eta_{c}$ geometry.

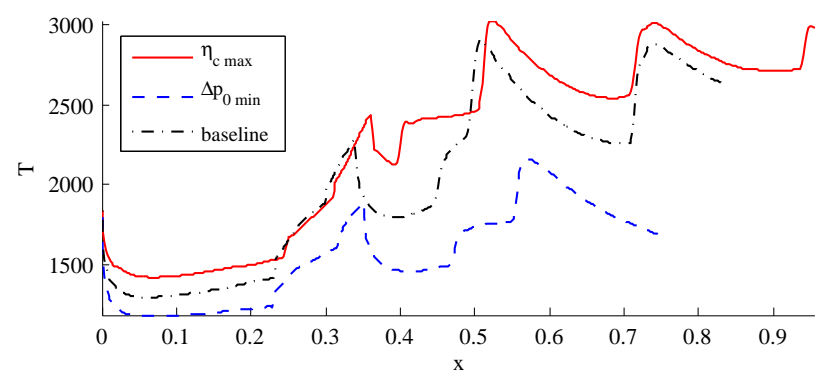

Fig. (11). Wall temperature distributions for optimised and baseline geometries.

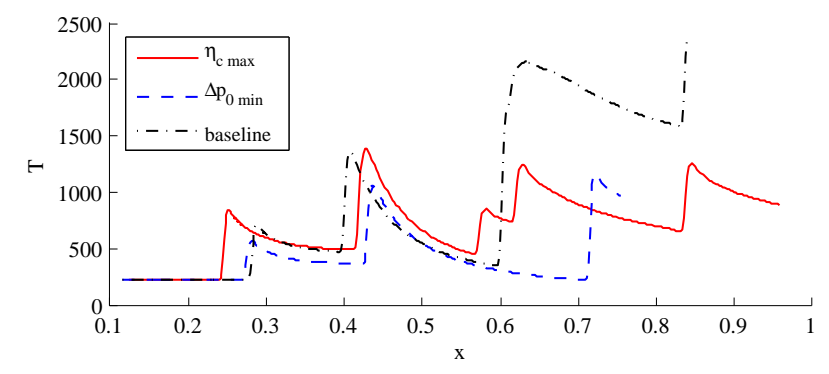

Fig. (12). Centreline temperature distributions for optimised and baseline.

\section{CONCLUSIONS}

The inlet and combustor geometries of axisymmetric scramjets have been optimised for double objectives: maximum combustion efficiency and minimum total pressure loss. Flowfields have been analysed for the two extreme cases on the Pareto optimal front in comparison with the baseline geometry. In this situation of inviscid flowfields and premixed fuel and air as well as relatively mild compression due to a fixed combustor radius, key geometric parameters that have major impact on the efficiencies have been identified to be: leading-edge nose tip radius, inlet compression, combustor length and divergence.

The capability of the advanced MDO / CFD approach has been demonstrated for inviscid inlet and combustor shape optimisation. The sophisticated design capability developed here and the insight into the geometric influence on the combustion process can be applied to a more integral optimisation including the nozzle and external part [28]. A further extension of the present study will lead to the inclusion of viscosity, which can account for various important factors in scramjet engine design, i.e. shock wave / boundary layer interactions and skin friction drag. 


\section{ACKNOWLEDGMENT}

Authors are grateful to Mr. Yohan Alazet at École Nationale Supérieure de l'Aéronautique et de l'Espace for his invaluable assistance in developing the mesh generation and optimisation methodology.

\section{NOMENCLATURE}

$$
\begin{array}{lll}
\overline{p_{0}} & =\text { Mass-averaged total pressure } \\
\Delta p_{0} & =\text { Mass-averaged total pressure loss } \\
\eta_{c} & =\text { Combustion efficiency } \\
c_{H_{2}} & =\text { Mass fraction ratio of hydrogen (fuel) } \\
M & =\text { Mach number } \\
p & =\text { Pressure }[\mathrm{Pa}] \\
T & =\text { Temperature }[\mathrm{K}] \\
l & =\text { Length [m] } \\
\theta & =\text { Angle }[\mathrm{deg}] \\
x & =\text { Streamwise coordinate }[\mathrm{m}] \\
r & =\text { Radial coordinate }[\mathrm{m}] \\
\text { subscripts } & \\
i & =\text { Values at inlet entrance } \\
e & =\text { Values at combustor exit } \\
\infty & =\text { Values of inflow }
\end{array}
$$

\section{REFERENCES}

[1] J. Tamagno, and O. Lindemann, Experimental Results on Supersonic Combustion, General Applied Science Laboratories, Ronkonkoma, NY, December 1962.

[2] I. T. Osgerby, H. K. Smithson, and D. A. Wagner, "Supersonic combustion tests with a double-oblique-shock SCRAMjet in a shock tunnel", AIAA J., vol. 8, no. 9, pp. 1703-1705, 1970.

[3] G. Y. Anderson, C. R. McClinton, and J. P. Weidner, "Scramjet performance", In: Scramjet Propulsion, E. T. Curran and S. N. B. Murthy Eds., Reston, VA: AIAA Progress in Astronautics and Aeronautics, 2000, vol. 189, pp. 369-446.

[4] A. Paull, R. J. Stalker and D. J. Mee, "Experiments on supersonic combustion ramjet propulsion in a shock tunnel", J. Fluid Mech., vol. 296, pp. 159-183, 1995.

[5] R. J. Stalker, A. Paull, D. J. Mee, R. G. Morgan, and P. A. Jacobs, "Scramjets and shock tunnels - The Queensland experience", Prog Aerosp Sci., vol. 41, pp. 471-513, 2005.

[6] A. Paull, H. Alesi, and S. Anderson, "HyShot flight program and how it was developed", AIAA 2002-5248, $11^{\text {th }}$ AIAA/AAF International Conference on Space Planes and Hypersonic Systems and Technologies, Orléans, France, September 2002.

[7] R. R. Boyce, S. Gerard, and A. Paull, "The hyshot scramjet flight experiment - flight data and CFD calculations compared", AIAA 2003-7029, $12^{\text {th }}$ AIAA International Space Planes and Hypersonic Systems and Technologies Conference, Norfolk: VA, December 2003.

[8] C. R. McClinton, "X-43 - Scramjet power breaks the hypersonic barrier: dryden lectureship in research for 2006", AIAA 2006-1-317, $43^{\text {rd }}$ AIAA Aerospace Sciences Meeting and Exhibit, Reno, NV, January 2006.
[9] D. C. Hunt, A. Paull, R. R. Boyce, and M. Hagenmaier, "Investigation of an axisymmetric scramjet configuration utilising inletinjection and radical farming", in proceedings of $19^{\text {th }}$ International Symposium on Airbreathing Engines Montreal, Canada, September 2009.

[10] J. R. McGuire, R. R. Boyce, and N. R. Mudford, "Radical farm ignition processes in two-dimensional supersonic combustion", $J$. Propulsion Power, vol. 24, no. 6, pp. 1248-1257, 2008.

[11] M. K. Smart, "Scramjets", Aeronautical J., vol. 111, no. 1124, pp. 605-620, 2007.

[12] M. K. Smart, and C. A. Trexler, "Mach 4 Performance of hypersonic inlet with rectangular-to-elliptical shape transition", J. Propulsion Power, vol. 20, no. 2, pp. 288-293, 2004.

[13] O. Baysal, and M. E. Eleshaky, "Aerodynamic design optimization using sensitivity analysis and computational fluid dynamics", AIAA 91-0471, 29 $9^{\text {th }}$ Aerospace Sciences Meeting, Reno, NV, January 1991.

[14] P. D. McQuade, S. Eberhardt, and E. Livne, "CFD-Based aerodynamic approximation concepts optimization of a two-dimensional scramjet vehicle", J. Aircr., vol. 32, no. 2, pp. 262-269, 1995.

[15] C. S. Craddock, "Computational Optimization of Scramjets and Shock Tunnel Nozzles", PhD Thesis, The University of Queensland, Australia, 1999.

[16] K. Deb, Multi-Objective Optimization using Evolutionary Algorithms, Wiley, New York, ISBN: 978-0471873396, 2001.

[17] T. Ray, and W. Smith, "A surrogate assisted parallel multiobjective evolutionary algorithm for robust engineering design", Eng Optim, vol. 38 , no. 8, pp. 997-1011, 2006

[18] T. Ray, A. Isaacs, and W. Smith, "Multi-Objective optimization using surrogate assisted evolutionary algorithm", (Introduction G. P. Rangaiah), Multi-objective Optimization: Tech Applications in Chemical Engineering, World Scientific, Singapore, 2008, pp. 131151 .

[19] N. R. Deepak, T. Ray, and R. R. Boyce, "Shape optimization of the nose cone for a hypersonic flight experiment trajectory", J. Spacecr Rockets [accepted], DOI: 10.2514/1.33826, 2008.

[20] C. Steffen, "Fuel injector design optimization for an annular SCRAMJet geometry", AIAA 2003-0651, 41 Aerospace Sciences Meeting and Exhibit, Reno, NV, January 2003.

[21] B. T. Sparkman, J. W. Chrissis, M. R. Gruber, and M. A. Abramson, "Optimization of a scramjet fuel injection array: An application of mixed variable generalized pattern search with kriging surrogates", AIAA 2008-5861, $12^{\text {th }}$ AIAA / ISSMO Multidisciplinary Analysis and Optimization Conference, Victoria, Canada, 2008.

[22] CFD++, Software Package, Ver. 8.11, Metacomp Technologies, Inc., CA, 2009.

[23] J. S. Evans, and C. J. Jr. Schexnayder, "Influence of chemical kinetics and unmixedness on burning in supersonic hydrogen flames", AIAA J., vol. 18, no. 2, pp. 188-193, 1980.

[24] Pointwise, Software Package, Ver. 16.02, Pointwise, Inc., TX, 2008.

[25] K. Deb, A. Pratap, S. Agarwal, and T. Meyarivan, "A fast and elitist multiobjective genetic algorithm: NSGA-II”, IEEE Trans. Evol. Comput., vol. 6, No. 2, pp.182-197, 2002.

[26] K. Deb, Optimization for Engineering Design: Algorithms and Examples, Prentice-Hall: New Delhi, India, 1995.

[27] A. Mack, J. Steelant, K. Hannemann, S. Karl, and J. Odam, "Mixing and combustion enhancement in a generic scramjet combustion chamber", AIAA 2006-8134, $14^{\text {th }}$ AIAA/AHI Space Planes and Hypersonic Systems and Technologies Conference, Canberra, November 2006.

[28] H. Ogawa, Y. Alazet, R. R. Boyce, A. Isaacs, and T. Ray, "Design optimisation of axisymmetric scramjets for access-to-space", in proceedings of $9^{\text {th }}$ Australian Space Science Conference, Sydney, September 2009.

This is an open access article licensed under the terms of the Creative Commons Attribution Non-Commercial License (http://creativecommons.org/licenses/by-nc/3.0/) which permits unrestricted, non-commercial use, distribution and reproduction in any medium, provided the work is properly cited. 